\title{
SISTEM AUTOMASI PERKEBUNAN DAN PEMANTAUAN CUACA MENGGUNAKAN AWS BERBASIS RASPBERRY PI
}

\section{Erfan Rohadi', Raka Admiral Abdurrahman², Ekojono ${ }^{3}$, Rosa Andrie Asmara ${ }^{4}$, Indrazno Siradjuddin ${ }^{5}$, Ferdian Ronilaya ${ }^{6}$, Awan Setiawan ${ }^{7}$}

\author{
1,2,3,4 Jurusan Teknologi Informasi, Politeknik Negeri Malang, Jl. Soekarno-Hatta No. 9, Malang 65141 \\ 5,6,7 Jurusan Teknik Elektro, Politeknik Negeri Malang, Jl. Soekarno-Hatta No. 9, Malang 65141 \\ Email: 1erfanr@polinema.ac.id, ${ }^{2}$ raka.flyhigh@gmail.com, ${ }^{3}$ ekojono2@polinema.ac.id, \\ ${ }^{4}$ rosa.andrie@polinema.ac.id, ${ }^{5}$ indrazno@polinema.ac.id, ${ }^{6}$ ferdian@polinema.ac.id, \\ 7 awan.setiawan@polinema.ac.id
}

(Naskah masuk: 14 Oktober 2018, diterima untuk diterbitkan: 30 Oktober 2018)

\begin{abstract}
Abstrak
Internet of Things (IoT) mengalami perkembangan yang sangat pesat dan menjadi topik yang layak untuk diperbincangkan dan dikembangkan saat ini. IoT merupakan sebuah metode yang bertujuan untuk memaksimalkan manfaat dari konektivitas internet untuk melakukan transfer dan pemrosesan data- data atau informasi melalui sebuah jaringan internet secara nirkabel, virtual dan otonom. Salah satu pemanfaatan IoT adalah sistem automasi. Sistem automasi pada umumnya menggunakan pengatur waktu (timer) untuk proses penyiraman tanaman. Penggunaan timer bertujuan agar penyiraman tanaman berjalan secara rutin tanpa bantuan manusia. Pengembangan sistem automasi ini dimulai dengan pembuatan prototype lahan tanaman cabai rawit di lahan $5 \mathrm{x}$ 2.5 meter, kemudian menyusun komponen-komponen yang dibutuhkan serta cara kerjanya. Selanjutnya dilakukan pemrograman sensor-sensor terhadap Raspberry Pi sebagai pengontrol dalam sistem tersebut berdasarkan kondisi yang telah diatur dan perubahan temperatur yang diterima oleh sensor. Setelah semua dilakukan, maka dilakukan pengujian terhadap sistem tersebut. Berdasarkan pengujian yang telah dilakukan, diketahui telah berhasil dilakukan penyiraman otomatis, baik secara reguler (pukul 06.00 dan 18.00) maupun penyiraman pendinginan. Pendinginan dilakukan jika suhu lebih dari 30 derajat celcius. Sistem automasi yang dikembangkan dengan uji tanaman cabai rawit menjanjikan untuk diterapkan pada pemanfaatan lahan di sekitar rumah.
\end{abstract}

Kata kunci: Internet of Things, Cabai Rawit, Raspberry Pi, Sensor, Automasi

\section{RASPBERRY PI-BASED FARMING AUTOMATION AND MONITORING SYSTEM USING AUTOMATIC WEATHER SYSTEM (AWS) (CASE STUDY: CHILI PLANTS)}

\begin{abstract}
Recently, The Internet of Things (IoT) has been implemented and become an interesting topic for discussion. IoT is a method that aims to maximize the benefits of Internet connectivity to transfer and process data or information through an internet network wirelessly, virtual and autonomous. One of the IoT's utilization is automation system. The automation system generally uses a timer for the plant watering process. The use of timers aims to water the plants routinely without human assistance. The development of this automation system begins with the making of the prototype of chili land in the field $5 \times 2.5$ meters, then compile the required components and how it works. Further programming of sensors to Raspberry Pi as a controller in the system based on the conditions that have been set and changes in temperature received by the sensor. As a result, the system has been successfully done automatic watering, both on a regular basis (at 06.00 and 18.00) and cooling watering. Cooling is done if the temperature exceeds more than 30 degrees Celsius. The automation system promises to be applied to the utilization of land around the house.
\end{abstract}

Keywords: Internet of Things, Chili, Raspberry Pi, Sensor, Automation

\section{PENDAHULUAN}

Internet of Things atau yang disingkat IoT mengalami perkembangan yang sangat pesat dan menjadi topik yang layak untuk diperbincangkan dan dikembangkan saat ini. Mengingat statistik yang dilansir oleh IHS Markit ${ }^{\circledR}$ pada tahun 2015 terdapat 15,4 milyar perangkat (devices) yang terhubung satu 
sama lain melalui jaringan Internet. Jumlah tersebut diperkirakan akan terus meningkat hingga mencapai 30,7 milyar perangkat (devices) yang terhubung pada tahun 2020 dan 75,4 milyar perangkat (devices) pada tahun 2025 (K. Claveria, 2017). IoT sendiri merupakan sebuah metode yang bertujuan untuk memaksimalkan manfaat dari konektivitas internet untuk melakukan transfer dan pemrosesan data-data atau informasi melalui sebuah jaringan internet secara nirkabel, virtual dan otonom. Pemanfaatan metode IoT sendiri sudah mulai masuk ke berbagai bidang, misalnya bidang pendidikan, telekomunikasi, pertanian, perkebunan, dan lain sebagainya.

Cabai merupakan tanaman hortikultura semusim, artinya adalah tanaman sumber vitamin, garam mineral, dan lain-lain yang dikonsumsi dari bagian yang berupa buah (cabai), berumur kurang dari satu tahun, tidak berbentuk pohon atau rumpun tetapi menjalar dan berbatang lunak (Badan Pusat Statistik, 2018). Selain itu, Cabai merupakan salah satu komoditas pertanian yang paling banyak diminati masyarakat Indonesia karena pada umumnya masyarakat Indonesia menyukai makanan pedas. Di sisi lain, saat ini perubahan gaya hidup dan perkembangan industri kuliner yang terus meningkat juga mempengaruhi permintaan cabai. Berdasarkan survei yang telah dilakukan BPS, produksi cabai rawit terus mengalami peningkatan. Sebagai perbandingan, produksi cabai rawit di Indonesia tahun 2014 sebesar 0,800 juta ton dan pada tahun 2013 sebesar 1,012 ton. Artinya mengalami peningkatan sebanyak 6,09 persen (Badan Pusat Statistik, 2014). Sedangkan untuk konsumsi cabai merah di Indonesia pada tahun 2014 mencapai kurang lebih $2,93 \mathrm{~kg}$ per kapita per tahun dan pada tahun 2013 mencapai 2,89 kg per kapita per tahun. Artinya mengalami peningkatan $1,45 \%$ (Suwandi, et.al., 2016). Peningkatan produksi tersebut seiring dengan perkembangan kuliner saat ini yang kebanyakan menggunakan cabai sebagai bahan utamanya. Namun, seiring perkembangan teknologi yang semakin maju seperti sekarang ini sangat menganjurkan bahwa pertanian yang maju dan progresif memerlukan suatu inovasi baru yang amat dibutuhkan untuk menggapai dan beradaptasi terhadap perubahan yang demikian cepat. Hasil analisis lain yang ditunjukkan oleh BPS menyatakan bahwa petani cabai yang memiliki luas garapan kurang dari 1 (satu) hektar menghasilkan pendapatan yang lebih sedikit dikarenakan biaya produksi tidak sebanding dengan biaya pendapatan (Winarno, F.G, et.al, 2017).

Berawal dari masalah tersebut, akan dibangun sebuah Sistem Automasi Perkebunan dan Pemantauan Cuaca Menggunakan Automatic Weather System (AWS) Berbasis Raspberry Pi. Aplikasi ini membantu pemantauan secara realtime mengenai kondisi tanaman cabai rawit yang sedang ditanam. Selain itu, untuk mempermudah pengguna dalam memantau tanamannya, akan ditampilkan informasi-informasi yang berkaitan dengan outlook cuaca dalam beberapa hari ke depan sehingga bisa dilakukan tindakan yang cepat, karena tanaman cabai rawit sangat sensitif terhadap perubahan iklim. Diharapkan dengan adanya sistem ini dapat membantu petani cabai rawit dalam skala kecil dalam memproduksi cabai rawit dengan jumlah yang besar dan mendorong generasi muda untuk bercocok tanam dengan teknologi terkini.

\section{METODOLOGI PENELITIAN}

Penelitian ini dilakukan sesuai dengan tahapantahapan sesuai dengan Fishbone Diagram yang ditunjukkan dalam Gambar 1 berikut.

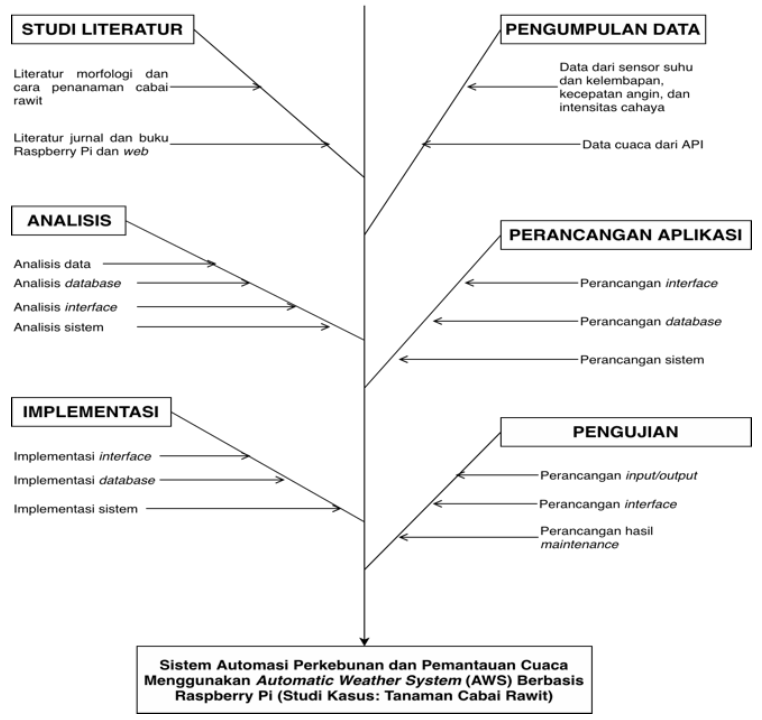

Gambar 1. Diagram Fishbone Langkah-Langkah Penelitian

\subsection{Perancangan Lahan Garapan}

Desain lahan yang akan digunakan untuk menanam tanaman cabai rawit memiliki ukuran $5 \mathrm{~m}$ x 2,5 m dengan total luasan $12,5 \mathrm{~m}^{2}$. Lahan tersebut nantinya akan ditanami cabai rawit sejumlah kurang lebih 40 tanaman. Spesifikasi lahan yang akan digunakan ditunjukkan pada Gambar 2 berikut.

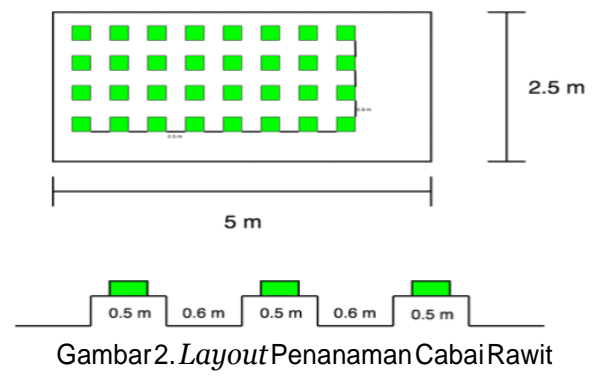

\subsection{Perancangan Perangkat Keras}

Perancangan perangkat keras bertujuan untuk merencanakan atau merancang perangkat keras sesuai dengan spesifikasi dan alur sistem yang akan dibuat. Perancangan perangkat keras dibuat dalam bentuk 
blok diagram yang terdiri dari susunan alat dan sistem secara umum, seperti yang digambarkan dalam Gambar 3.

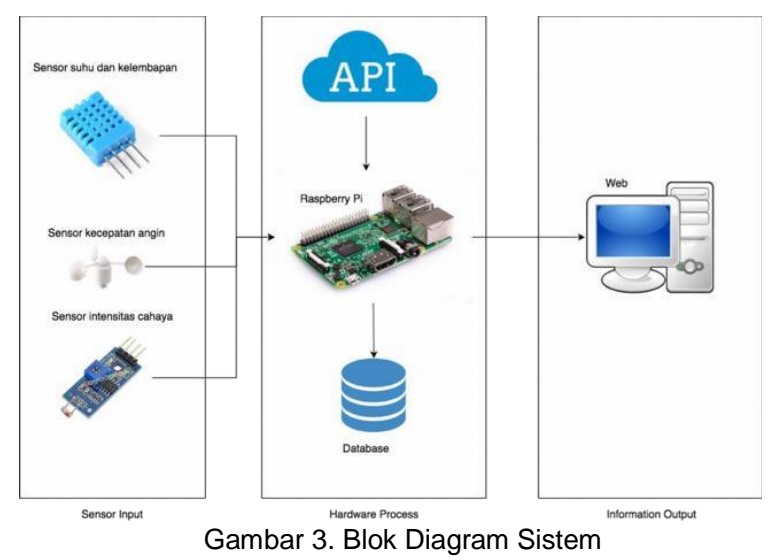

Pada sistem automasi ini, sensor-sensor melakukan pengambilan data dari sensor suhu, kelembapan udara, kecepatan angin, dan intensitas cahaya. Sensor suhu dan kelembapan udara akan mengukur suhu di ladang yang akan digarap, sedangkan sensor intensitas cahaya akan mengukur intensitas cahaya matahari di ladang yang akan digarap. Kemudian, setelah sensor-sensor mendapatkan semua data pengukurannya, makadatadata tersebut akan dimasukkan ke dalam database yang terdapat pada Raspberry Pi. Data-data pemantauan sensor yang ada di dalam Raspberry Pi tersebut akan dibandingkan dengan data yang berasal dari API OpenWeatherMap. Data tersebut dibandingkan bertujuan untuk mengecek apakah data dari sensor-sensor tersebut akurat atau tidak sekaligus menentukan cuaca di daerah tersebut (di lahan garapan). Setelah data-data dari sensor dan API tersebut sudah disatukan, maka selanjutnya akan ditentukan pola penyiraman tanaman cabai rawit di lahan garapan tersebut berdasarkan suhu, kelembapan, dan intensitas cahaya matahari, sedangkan untuk kecepatan angin akan menentukan kapan paranet akan ditutup.

\subsection{Perancangan Perangkat Lunak}

Ketika sistem dijalankan, pertama kali sistem akan melakukan pengambilan data- data yang berasal dari sensor suhu, kelembapan udara, kecepatan angin, dan intensitas cahaya. Kemudian, data-data tersebut dipadukan dengan data-data yang berasal dari API OpenWeatherMap. Selanjutnya, akan dicek apakah suhu lingkungan antara $21^{\circ} \mathrm{C}$ hingga $30^{\circ} \mathrm{C}$. Jika memenuhi syarat suhu tersebut, maka akan dicek kembali apakah cuacanya cerah (berawan) atau hujan. Jika cuacanya cerah (berawan), maka penyiraman dilakukan sebanyak dua kali sehari setiap pagi (jam 06:00) dan sore (jam 18:00) agar menghindari penguapan (evaporasi) yang berlebihan dan pertumbuhan tanaman lebih optimal (Winarno, F.G, et.al, 2017).

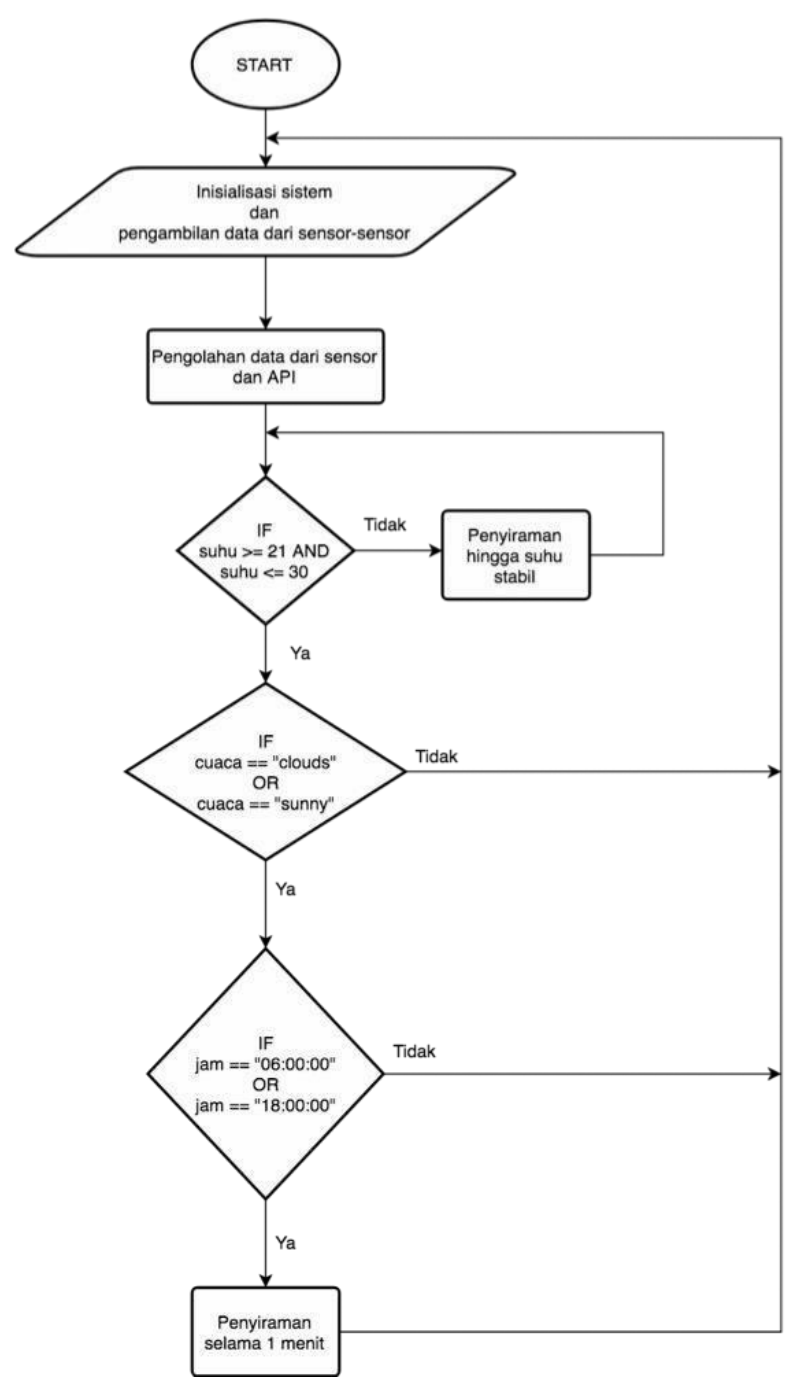

Gambar 4. Diagram Alir Penyiraman

Jika cuacanya hujan, maka tidak perlu dilakukan penyiraman. Jika suhu tersebut lebih dari $30^{\circ} \mathrm{C}$, maka akan dilakukan pendinginan dengan cara penyiraman hingga suhu di lahan garapan stabil.

\section{HASIL DAN PEMBAHASAN}

\subsection{Implementasi Lahan Garapan}

Lahan yang digunakan untuk menanam cabai rawit ini memiliki luas $12,5 \mathrm{~m} 2$ dengan panjang lahan $5 \mathrm{~m}$ dan lebar lahan 2,5 m. Luas lahan tersebut dibuat bedengan sebanyak 20 buah dengan jarak antar tanaman $60 \mathrm{~cm}$ serta jarak antar baris $50 \mathrm{~cm}$. Setelah lahan tanaman cabai rawit sudah terpasang, selanjutnya memasang pipa-pipa dan melubanginya dengan jarak yang sama dengan jarak antara tanaman cabai rawit, seperti yang digambarkan dalam Gambar 5 berikut.

\subsection{Implementasi Sistem}

Sistem dibuat setelah masing-masing perangkat keras dan perangkat lunak sudah dipasang dengan baik. Sistem ini akan memantau berdasarkan parameter suhu, kelembapan, kecepatan angin, dan intensitas cahaya. 


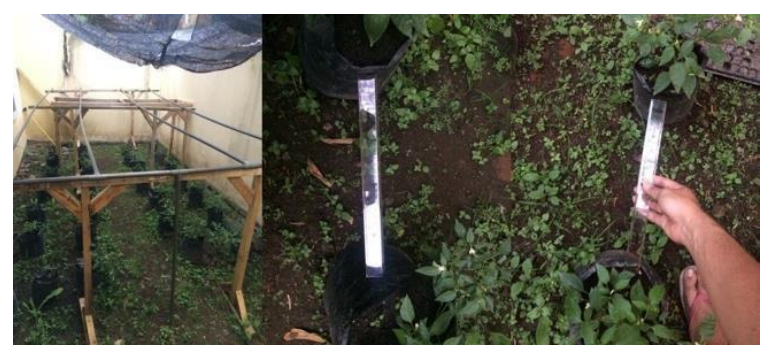

Gambar 5. Implementasi Lahan Garapan

Semua parameter tersebut akan dilakukan pemantauan melalui sistem berbasis web pada jaringan lokal dan internet. Kemudian, sistem ini akan melakukan automasi penyiraman reguler dan pendinginan. Penyiraman reguler dilakukan sebanyak dua kali sehari setiap pagi (jam 06:00) dan sore (jam 18:00) agar menghindari penguapan (evaporasi) yang berlebihan dan pertumbuhan tanaman lebih optimal (Winarno, F.G. et.al, 2017). Sedangkan untuk penyiraman pendinginan dilakukan jika suhu di lahan garapan lebih dari $30^{\circ} \mathrm{C}$.

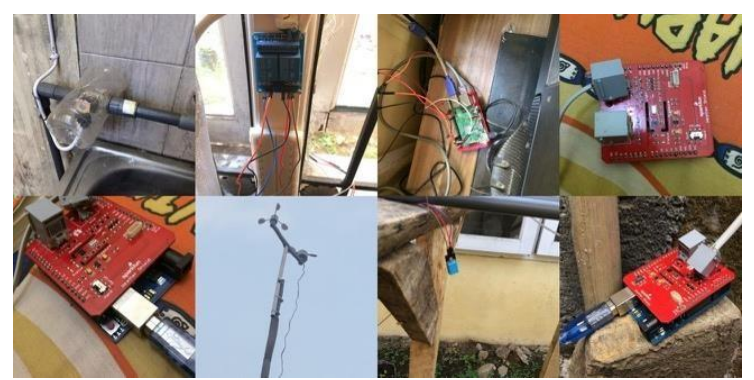

Gambar6. Implementasi Relay dan Sensor Suhu, Kelembapan, Kecepatan Angin, dan Intensitas Cahaya

Selain sistem automasi untuk penyiraman reguler, sistem ini juga melakukan automasi jika sensor yang terpasang pada lahan garapan error atau tidak membaca parameternya. Data yang diambil adalah nilai dari masing-masing sensor pada seminggu ke belakang, kemudian dicari nilai yang sesuai, dan akan dilakukan sebuah action. Action bersifat sementara hingga sensor tersebut selesai dimaintenance.

\section{Sensor Suhu}

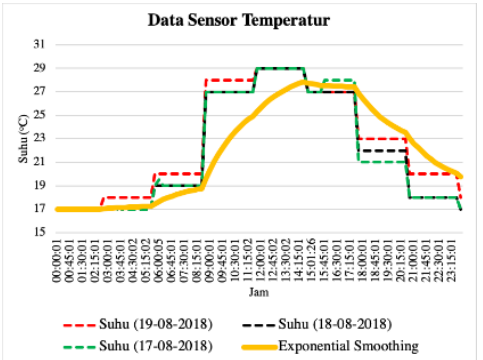

Gambar 7. Grafik Data Sensor Temperatur Udara

\section{Sensor Kelembapan Udara}

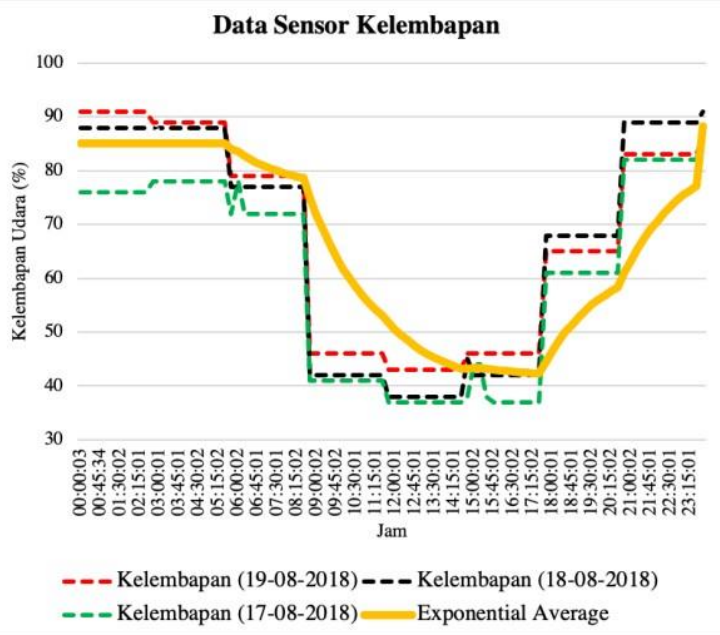

Gambar 8. Grafik Data Sensor Kelembapan Udara

Grafik di atas menggambarkan data kelembapan udara yang diambil selama tiga hari, grafik warna merah dengan garis putus-putus menggambarkan data sensor kelembapan udara yang diambil pada tanggal 19 Agustus 2018, grafik warna hitam dengan garis putus-putus menggambarkan data sensor kelembapan udara yang diambil pada tanggal 18 Agustus 2018, dan grafik warna hijau dengan garis putus-putus menggambarkan data sensor kelembapan udara yang diambil pada tanggal 17 Agustus 2018. Exponential smoothing dari rata- rata dari ketiga data kelembapan udara tersebut. Dari grafik tersebut menunjukkan bahwa data kelembapan udara tersebut memiliki trend yang sama.

\section{Sensor Kecepatan Angin}

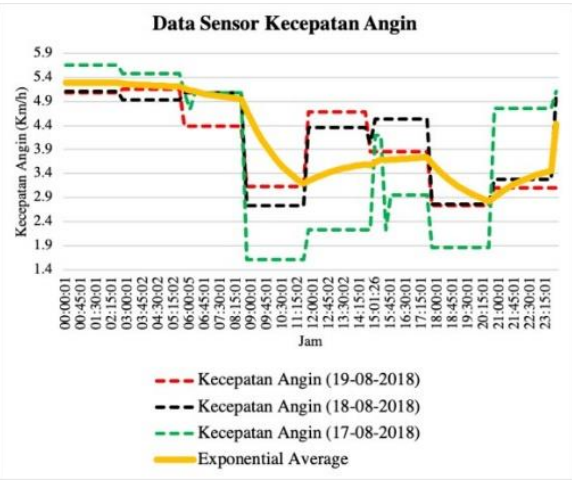

Gambar 9. Grafik Data Sensor Kecepatan Angin

Grafik di atas menggambarkan data kecepatan angin yang diambil selama tiga hari, grafik warna merah dengan garis putus-putus menggambarkan data sensor kecepatan angin yang diambil pada tanggal 19 Agustus 2018, grafik warna hitam dengan garis putusputus menggambarkan data sensor kecepatan angin yang diambil pada tanggal 18 Agustus 2018, dan grafik warna hijau dengan garis putus-putus menggambarkan data sensor kecepatan angin yang diambil pada tanggal 17 Agustus 2018. 
Grafik warna oranye tersebut merupakan hasil exponential smoothing dari rata- rata dari ketiga data kecepatan angin tersebut. Dari grafik tersebut menunjukkan bahwa data kecepatan angin tersebut memiliki trend yang sama.

4.

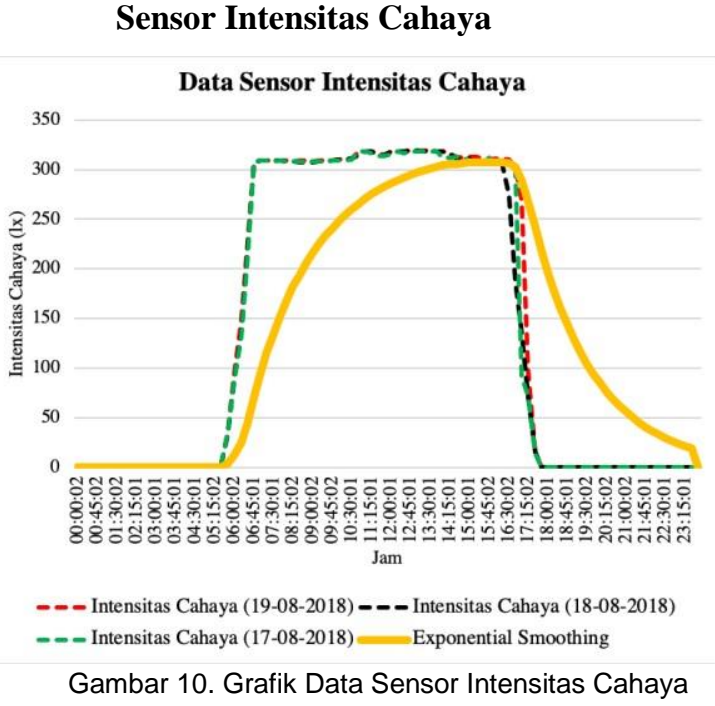

Grafik di atas menggambarkan data intensitas cahaya yang diambil selama tiga hari, grafik warna merah dengan garis putus-putus menggambarkan data sensor intensitas cahaya yang diambil pada tanggal 19 Agustus 2018, grafik warna hitam dengan garis putus-putus menggambarkan data sensor intensitas cahaya yang diambil pada tanggal 18 Agustus 2018, dan grafik warna hijau dengan garis putusputus menggambarkan data sensor intensitas cahaya yang diambil pada tanggal 17 Agustus 2018. Grafik warna oranye tersebut merupakan hasil exponential smoothing dari rata- rata dari ketiga data intensitas cahaya tersebut. Dari grafik tersebut menunjukkan bahwa data kecepatan angin tersebut memiliki trend yang sama.

\section{KESIMPULAN}

- Hasil ujicoba menunjukkan bahwa semua sensor berfungsi dengan baik, data dari keempat sensor terbaca dan diolah dalam Raspberry $\mathrm{Pi}$ untuk menjalankan sistem otomasi pemeliharaan tanaman cabai.

- Sistem automasi yang dikembangkan dengan uji tanaman cabai rawit menjanjikan untuk diterapkan pada pemanfaatan lahan di sekitar rumah.

\section{DAFTAR PUSTAKA}

JATNIKA. Penjelasan Raspberry Pi. Retrieved from: https://agiljatnika.wordpress.com/2013/09/ 16/penjelasan-raspberry-pi/
AZZAMY. Cara Budidaya Menanam Cabe Rawit yang Baik di Polybag atau Pot. Retrieved from: https://mitalom.com/cara-menanamcabai-rawit-dalam-polybag- atau-pot-agartahan-lama-dan-berbuah-lebat/

A. HARIYANTO, Sistem Manajemen Basisdata, Bandung: Penerbit Informatika, 2004.

B. RAHARJO, Modul Pemrograman Web (HTML, PHP, \& MySQL), Bandung: Penerbit Modula, 2016.

B. RAHARJO, Mudah Belajar PHP Teknik Penggunaan Fitur-Fitur Baru dalam PHP5, Bandung: Penerbit Informatika, 2015.

BADAN PUSAT STATISTIK (2018). Istilah Pertanian dan Pertambangan. Retrieved from: https://www.bps.go.id/subject/55/hortikultu ra.html\#subjekViewTab1

BADAN PUSAT STATISTIK (2015). Produksi Cabai Besar, Cabai Rawit, Dan Bawang Rawit Tahun 2014. In Berita Resmi Statistik, Jakarta, Badan Pusat Statistik, 2015, pp. 1-2.

DIGGE, JYOTHI \& DIGGE, YASHRAJ (2012). Stereo Vision For Robotics. International Journal of Computer Applications in Technology, 32-39

DINUS. Diagram Fishbone. Retrieved from: http://dinus.ac.id/repository/docs/ajar/Diagr am_Fisbone.pdf

FERIDI. Mengenal RESTful Web Services.Retrieved from: https://www.codepolitan.com/mengenalrestful-web-services

DANIEL (2004). Software Quality Assurance From Theory to Implementation. Edinburgh: Pearson Education Limited

SIANIPAR (2015). HTML5 \& CSS3 Belajar Dari Kasus. Bandung: Penerbit Informatika

SIANIPAR (2015). Pemrograman Python (Teori dan Implementasi). Bandung: Penerbit Informatika

P. A. E. PRATAMA (2014). Smart City beserta Cloud Computing dan Teknologi- Teknologi Pendukung Lainnya. Bandung: Penerbit Informatika

I. SOMMERVILLE (2011). Software Engineering 7th Edition. Boston: Pearson Education, Inc.

IHSAN (27 Maret 2018). Syarat Tumbuh Tanaman Cabai Merah (Capsicum annuum L). Retrievedfrom:https://www.petanihebat.com/syara t- tumbuh-tanaman-cabai- merahcapsicum- annuum-1/.

INDOWARE. Light Sensor BH1750 BH1750FVI. Retrieved from: https://www.indoware.com/produk-2855-light-sensor- bh1750bh1750fvi.html

CLAVERIA (28 April 2017). 13 Stunning Stats on The Internet of Things. Retrieved from: https://www.visioncritical.com/internet-ofthings-stats/

NURHAYATI dan A. J. (2016). Pengaruh Kecepatan Angin Terhadap Evapotranspirasi Berdasarkan Metode Penman di Kebun Stroberi Purbalingga" 
716 Jurnal Teknologi Informasi dan Ilmu Komputer (JTIIK), Vol. 5, No. 6, November 2018, hlm. 711-716

Elkawnie: Journal of Islamic Science and Technology, 2, 21-28

R. FACHRI. Tutorial Arduino Mengukur Kecepatan Angin dengan Anemometer. Retrieved from: http://electricityofdream.blogspot.co.id/201 6/10/tutorial-arduino- mengukurkecepatan.html

D. ALI (15 Mei 2017). Diagram Fishbone. Retrieve from:https://sis.binus.ac.id/2017/05/15/fishbonediagram/

HARYANDI (15 September 2016). Mengenal RESTful API. Retrieved from:। https://kudo.co.id/engineering/2016/09/15/ mengenal-restful-api/

SUWANDI, et.al. (2016). Outlook Cabai. Jakarta: Pusat Data dan Sistem Informasi Pertanian Sekretariat Jenderal Kementerian Pertanian, pp. 17-18.

WINARNO F.G, dkk (2017). Produksi dan Perdagangan Cabai. In Cabai Potensi Pengembangan Agrobisnis dan Agroindustri. Jakarta: PT. Gramedia Pustaka Utama, pp. 18-19. 
